\title{
CLIMATE CHANGE AND HUMAN HEALTH
}

\author{
By \\ El Samra G H \\ Professor of Occupational and Environmental Medicine \\ Cairo University
}

\begin{abstract}
:
Climate is the prevailing conditions of temperature, rainfall, humidity, wind, etc... that are characteristic of a certain region over a long period of time usually exceeding 20 years. Earth's climate changes naturally between warmth and ice ages but the changes occur over thousands of years. Within the last 150 years, industrial, agricultural and civic activities have resulted in acceleration of these changes due to the accumulation in the atmosphere of earth of increasing concentrations of certain gases known as the greenhouse gases (GHGs). These include: $\mathrm{CO}_{2}$, methane, $\mathrm{NO}_{x}, \mathrm{CFCs}, .$. This resulted in warming of the earth's surface mean temperature, deep ocean warming, melting of the alpine and polar ice caps and the spread of certain diseases, among other changes. Several of these changes have affected human health.

Heat waves have resulted in increased death rates especially among the elderly and those suffering from cardio-respiratory diseases. The effect of cold, stormy weather is less pronounced. Increased air pollution will cause more photochemical pollutants and increased pollens and fungal spores resulting in more asthma and respiratory ailments. People living in temperate climates will suffer less but lower socio-economic standards will exacerbate their sufferings. Due to migration of disease vectors and increase of their activity, vector-borne diseases will spread beyond their current geographical limits. Infectious diseases are now emerging, resurging and undergoing redistribution on a global scale. Pests will flourish. There will be more water-borne and food-borne diseases. Malnutrition will result from reduced crop production due to loss of land and water resources, farm animal diseases and destruction of fisheries. Extreme weather events will be more frequent and more severe. Floods will cause death, injury and destruction of land, crops and property and displacement of population resulting in overcrowding, poor hygiene, malnutrition and disease epidemics. Drought will cause malnutrition and disease, and storms will cause death and destruction. Sea level rise will cause inundation of coastal areas, loss and salinization of fertile land and displacement of population.
\end{abstract}


In Egypt, water resources may increase by $30 \%$ or be reduced. Parts of the Nile Delta will be submerged and 8.5 million people will be displaced from their homes.

There are interactions between global warming and ozone depletion which will result in an increase in UVB exposure.

Abbreviations :

GHGs : Greenhouse gases

CFCs : Chlorofluorocarbons

UVR : Ultraviolet rays

UVB : Ultraviolet B rays.

Key words :

Climate change - Greenhouse gases - Extreme weather events - sea level rise - Ozone depletion.

\section{Climate Change}

\section{(Global Warming)}

Climate : is the prevailing conditions of temperature, rain fall, humidity, wind, etc .... that are characteristic of a certain region, over a long period of time exceeding 20 years.

Weather : means the atmospheric conditions prevailing at a specific time and place with respect to heat or cold, humidity, sunshine, rain fall, fog, wind velocity, etc....

Research has proved that the climate of PLANET EARTH changes naturally due to geophysical factors. This occurs very slowly in cycles of freezing, repeated about every 100000 years, separated by periods of warmth that extend about 20000 years; without man having anything to do with this (El Shahawi, 2008).
Research has also proved that an increase in the concentration of $\mathrm{CO}_{2}$ in the atmosphere has always preceded the periods of warmth, possibly due to volcanic eruptions (El Shahawi, 2008).

Within the last 150 years, rapid changes have been observed in the earth's climate pointing to human activities being the cause. Industrial, agricultural and civic activities are now so great that the gaseous composition of the lower and middle atmosphere (troposphere and stratosphere) has been changing; an observation which is affecting the world climate as well as many of the natural ecosystems. The accumulation of carbon dioxide and the rate of atmospheric warming have quickened, and that polar and alpine ice masses are melting at rates not possible several years ago, and the deep ocean is heating up (Epstein and Leaf, 2007). 
Global warming has been traced to the increased concentration of certain gases in the atmosphere, duly called “ Greenhouse Gases (GHGs) “. These include carbon dioxide ( from burning of fossil fuel and deforestation), methane (from decaying organic matter, cement manufacture and cattle breeding ), nitrous oxide ( from fertilizers and burning fossil fuel ), chlorofluorocarbons (CFCs) ( from aerosols and refrigerants), ozone, water vapour and aerosols. The concentration of carbon dioxide increased from 270 ppm before the industrial revolution to $360 \mathrm{ppm}$, due to human activities (El Shahawi, 2008).

Water vapour contributes $2 / 3$ of the greenhouse effect and all other gases contribute

1/3 (El Shahawi, 2008). If there were no GHGs in the atmosphere, the surface of the earth would be about $40^{\circ} \mathrm{C}$ lower than it is today, and life as we know it would not be possible ( Epstein and Leaf, 2007).

Solar radiation passes through the atmosphere (including short-wave infrared radiations ), some of which is reflected by the atmosphere and earth's surface. The greater part of the solar radiation reaches the earth's surface where the solar energy is absorbed and warms it. Solar energy is converted to heat causing the emission of long-wave infrared radiation back to the atmosphere. Some of these radiations pass through the atmosphere and is lost to space, and some is absorbed by the GHGs and is re-emitted to the earth. The direct effect is warming of the earth's surface and the troposphere.

\section{Consequences of global warming} (Epstein and Leaf,2007 and McMichael et al., 1996) :

a. Earth's mean temperature close to the surface is increasing, especially at night. A crucial element is lack of letup at night. It is predicted that by the year 2100 global mean temperature will have increased by $1-3.5^{\circ} \mathrm{C}$.

b. Increased frequency of extreme weather events.

c. By the end of 2100 , the sea level is predicted to have risen by $18-58 \mathrm{~cm}$, due to melting of ice and expansion of water in the oceans.

d. Sea level rise will result in destruction of coastal cities and structures, displacement of inhabitants, inundation of fertile agricultural land, destruction of coral reefs and slowing down of tourist activities.

e. Subsoil salty water will rise due to sea level rise, with salinization of fertile agricultural land. 
f. Even if GHG concentrations were stabilized, sea level rise will continue for several decades (McMichael et al., 1996).

g. Rain fall over different regions of the earth will change, with increased incidence of floods, drought and change in water resources of rivers.

Future predictions are educated guesses based upon complexity of mathematical models, beset by uncertainties due to various interacting factors (McMichael et al., 1996).

\section{Climate Change and Human Health}

Climate-related health effects can be discussed under several headings (McMichael et al., 1996) :
a. - Heat, cold and air pollution
b. - Effect on biological disease agents
c. - Climate, food production and nutrition
d. - Extreme weather events, environmental refugees and crowding.

e. - Sea level rise.

\section{I . Heat , Cold and Air Pollution :}

\section{Heat and Cold:}

Earth's mean surface temperature is increasing, especially at night.

a. Heat waves can cause heat exhaustion, heat stroke and death especially among those at extremes of age and those suffering from cardiovascular and other chronic diseases. Death rates increase with the increase of the heat load, rapid rate of change and longer duration .

Climate change would exacerbate an already existing " urban heat island effect".

In tropical areas, people seem to be less severely affected by heat waves since temperatures do not greatly exceed the prevailing mean temperature, and population would have acclimatized to hot weather and adopted new lifestyles (Epstein and Leaf,2007) .

Hot work environment increases accident rate, decreases the ability to do physical work and has implications for mental task ability (Nerlander, 2009).

b. Very cold and, more so, stormy weather is responsible for winter-time excess

mortality. Winter-time mortality may be - in part - due to seasonal pattern of respiratory infections and to the interannual variability in the virulence of influenza strains. 
In temperate climates death rates are higher in winter and increase as temperature decreases.

Small rise in temperature may reduce the risk of respiratory infection since people spend less time indoors.

Increase in summer mortality will be greater than reduction in winter mortality. The net result is an increase in mortality rate (McMichael et al.,1996).

Factors influencing vulnerability to stressful weather :

a. Age and state of health : the elderly, the very young, those with decreased mobility and patients with cardiovascular disease have impaired physiological coping.

b.Urban heat island

c.Socio-economic disadvantage

- Low income

- Higher urban density

- Poor sanitation

- $\quad$ Lack of access to air conditioning

- Low educational level (McMichael et al.,1996 and McMichael et al., 2003) .

Intraseasonal-seasonal variation in heat-related mortality is due to : a. Short-term displacement of deaths (many deaths would have died soon after the wave due to other causes).

b. Impact of successive heat waves showing progressively lower mortality due to :

- Natural selection

- Physiological adaptation.

\section{Air Pollution :}

a. Warming reduces dispersion and dilution of air pollutants, enhances formation of photo-chemical smog, increases release of pollens and fungal spores causing respiratory troubles, hay fever, and fungal infections of the lung; and asthma is aggravated by cold and sand storms ( McMichael et al., 2003).

b. Acid precipitation leaches metals thus increasing their levels in plants, damages fresh water ecosystems reducing fish population, thus relieving mortality pressure on mosquito larvae.

In marine ecosystems it leads to eutrophication and hazardous algal blooms (Epstein and Leaf, 2007 and McMichael et al.,1996).

\section{Effect on Biological Disease} Agents :

\section{Disease Vectors and Intermediate} Hosts : 
a. Warming is expected to increase the coverage of malaria transmission zone from $45 \%$ of the world population to $60 \%$ by the latter half of the $21^{\text {st }}$ century (McMichael et al., 1996 and Epstein, 1997). This is equal to $60-80$ million more cases of malaria annually, mostly in tropical and subtropical regions and less protected temperate zones.

b. Warming is also expected to increase mosquito survival rates in temperate areas unless precipitation rate and humidity are not favourable. Warming without additional precipitation may serve to reduce mosquito longevity and reduce malaria transmission in tropical areas. Humidity affects survival, feeding habits and reproduction of the mosquito. Warming increases the metabolic activity of the insect leading to more biting and laying more eggs (McMichael et al. 1996; Epstein, 2005 and Epstein and Leaf, 2007).

c. Precipitation can provide more breeding places, however, floods can kill larvae or wash them away, and wind helps passive dispersion of the mosquito (Nerlander, 2009).

d. Warming affects the extrinsic cycle of the malaria parasite. e. Unless temperatures become too high for the snail and parasite to reduce the transmission potential, Schistosomiasis can spread beyond the current distribution limits, especially in less developed countries. Water contact increases in warmer weather. Temperature influences snail reproduction and growth and schistosome mortality, infectivity and development in the snail. Transmission potential is predicted to decrease in currently endemic areas because temperature will be too high for the snail and parasite ( McMichael et al., 1996).

f. Displacement of the population, due to drought, extreme weather events and sea level rise, brings man into areas where zoonotic diseases are being transmitted among wild life thus leading to emerging infections. These are caused by introducing or disseminating an existing agent among human population which did not develop immunity to this infection before. Infectious diseases are currently emerging, resurging or undergoing redistribution on a global scale (Epstein and leaf, 2007 ; McMichael et al., 1996 and Epstein, 1997). 


\section{Pests :}

a. Change in climate and land use can cause an increase in rodent population and an increased incidence of diseases associated with them like plague and leptospirosis.

b. Prolonged droughts interrupted by heavy rains favour population explosion of insects and rodents. Floods drive rodents from their burrows (Epstein and Leaf, 2007; McMichael et al., 1996; Epstein, 1997 and Epstein, 2005).

c. Flies can flourish in temperate zones due to warm weather; however, dry summer in temperate areas can cause reduction in numbers.

d. Extreme weather events destroy breeding places.

\section{Diseases Related to Water Supply} and Sanitation :

a. Scarcity of water causes increased concentration of polluting pathogens; and increases the incidence of " water washed diseases" like scabies, trachoma and conjunctivitis (Nerlander, 2009) .

b. The use of poorer quality water increases the incidence of diarrhoeal diseases. c. During floods, community water supply may be contaminated if sewage systems are disrupted, thus increasing foecal-oral transmission (Nerlander, 2009).

d. Cholera outbreaks have been observed during drought, floods and environmental emergencies causing mass migration. They also followed coastal algal blooms caused by warmer sea-surface water especially if contaminated by urban effluent (McMichael et al., 1996)

There is evidence that cholera vibrio can be harboured in marine planktons and is activated when conditions become favourable (McMichael et al., 1996; Epstein, 1997 and Epstein and Leaf, 2007).

\section{Food-borne Diseases :}

a. Warmer weather causes increased incidence of food-borne diseases and bacterial food poisoning.

b. Fasciola and food-borne trematodes are affected through the effect of warming on the intermediate host snail.

c. Due to algal blooms, toxic algae may affect man indirectly through fish and shell-fish feeding on them (McMichael et al., 1996). 


\section{Person-to-person Infections :}

The incidence of meningococcal infection is likely to increase.

\section{Climate, Food Production and}

\section{Nutrition :}

Long-term climate change could affect food production through the effect on :

Crops

Live stock and

Fisheries.

\section{Crops :}

Crop production is decreased through :

a. Loss of land through sea level rise and associated salinization.

b. Water resources for irrigation will be affected by change in geographical distribution of rain fall. Increased temperature of air and of the oceans will result in more evaporation, more clouds, rain and snow. This will occur mainly in coastal areas, while the interior of the continents will be drier and hot leading to drought, a condition unfavourable to grow most of the present day agriculture (Epstein and Leaf, 2007).

c. Temperatures favourable for growing grains will move to higher latitudes, but whether fertile soils, adequate rain fall and the essential elements for optimal growth will exist in higher latitudes is uncertain (Epstein and Leaf, 2007).

d. In Egypt there may be an increase in the Nile flow by $30 \%$ or a reduction by about $30-60 \%$ (Ministry of State for Environmental Affairs, 2006).

e. Pollutants resulting from industrial activities and consumption of fossil fuel ( $\mathrm{SO}_{2}$ and $\mathrm{NO}_{\mathrm{x}}$ ), ammonia, $\mathrm{H}_{2} \mathrm{~S}$ and dimethyl sulphide are toxic to plants (Epstein and Leaf, 2007).

f. Cities are founded near rich agricultural land. Rapid urbanization causes cities to expand encroaching on the most fertile crop land. It is the combined effect of climate change, population increase and expectations of a higher standard of living that lead to water and land scarcity for crop production posing serious questions about food sufficiency (Epstein and Leaf, 2007).

g. Warming may result in more crop yield if other conditions are favourable; however, grain production is expected to decrease by $30 \%$. It is more certain that negative impacts would occur in tropical regions where large populations already suffer from malnutrition and limited resources to adapt . 
h. Extreme weather events may destroy land and crops.

i. Agricultural pests are expected to flourish and invade new areas.

\section{Live Stock :}

a. Climate change affects health, growth, reproduction and dairy production of farm animals.

b. Increased incidence of animal diseases.

c. Heat stress affects dairy cows especially the younger ones.

\section{Fisheries :}

Extreme weather events destroy breeding places .

Adaptation to climate change in food production could be undertaken. In some developing countries, financial cost could be a limiting factor.

On a global level, countries that currently provide food aid to populations suffering from malnutrition may find themselves less able to maintain the aid level.

In the absence of climate change, people who would be at risk of hunger in the year 2060 are estimated at 640 million. Due to climate change, an additional 40 300 million will be at risk (McMichael et al., 1996).

\section{Extreme Weather Events :}

Studies indicate that the possibility of extreme weather events has doubled or even quadrupled with global warming.

Climate change will affect the frequency , severity, timing and

duration of extreme weather events, which has been observed during the last few decades. Extreme weather events include ;

\section{Floods}

Drought

Wind storms / rain storms and

Forest fires.

\section{Floods :}

Climate change is expected to cause changes in timing, regional pattern and intensity of rain fall, especially the number of days when heavy rain occurs.

Heavy rains and sea level rise may aggravate flooding especially in coastal areas.

Effects of floods include (McMichael et al., 1996) :

a. Drowning, injury and death.

b. Population displacement, overcrowding, poor hygiene and outbreaks of diarrhoea and respiratory disease. 
c. Destruction of food supplies and malnutrition especially for children.

d. Disruption of water and sewage systems and contamination of drinking water by municipal, agricultural and industrial waste.

e. Psychosocial problems and worry about future floods.

f. Economic loss.

\section{Drought :}

Effects of drought :

a. Diseases due to drinking unsafe water.

b. Increased incidence of water-washed diseases and diseases due to poor hygiene.

c. Reduced food production and increased incidence of malnutrition and starvation.

d. Food toxicity due to having to eat unfamiliar foods.

\section{Wind Storms / Rain Storms :}

( cyclones, hurricanes and typhoons )

Often associated with flooding. Effects :

a. Drowning, trauma and crush injuries.

b. Damage to property.

c. Damage to live-stock and fisheries. d. Destruction of crops and food stores.

\section{Forest Fires :}

Triggered by drought, heat waves, low humidity and high winds.

Effects :

a. Extensive air pollution and inhalation of smoke

b. Burns and death

c. Destruction of crops

d. Destruction of property .

Extreme Weather Events are accompanied by (McMichael et al., 1996) :

a. Breakdown of sanitation.

b. Collapse of health care infrastructure and lack of effective epidemiological monitoring.

c. They have been accompanied by malaria outbreaks, toxic algal . blooms and water-borne diseases like typhoid, hepatitis A, bacillary dysentery and cholera (Epstein and Leaf, 2007).

d. Psychological problems are frequent following extreme weather events. They affect the victims, rescuers and health and social workers.

In the short-term, disasters tend to unify the community. In the long-term, conflicts 
about food and dwelling become intensified and community structure weakened.

The magnitude and duration of psychological symptoms depend upon:

a. Nature of the event.

b. Structure of the local community, degree of community disruption.

c. Age.

d. Resources to re-establish oneself in relation to needs.

e. Suddenness and unexpectedness of the event.

f. Persistence of visual signs.

g. Bereavement, homelessness and unemployment.

Symptoms of post-traumatic stress disorder include :

a. Traumatic neurosis.

b. Persistent feeling of unsolved grief.

c. Survivor shame.

d. Impotent rage and hopelessness.

e. Anxiety, depression and aggressive behaviour.

f. Developmental problems in children.

Post-traumatic stress disorder and longterm psychiatric problems may persist for years.

\section{Other consequences of extreme weather events :}

Problem of environmental refugees and their living conditions.

Conflict between countries over scarce water resources and influx of refugees.

Civil unrest if there is food shortage or displacement.

Vulnerability to the health impact of extreme weather events is affected by (McMichael et al., 1996) :

a. Age : the very old, the very young and the less mobile have lower resistance to disease and poorer resources.

b. State of health, the chronically ill and the handicapped.

c. Population growth can lead to the concentration of population in high risk areas.

d. Slum areas and poor housing conditions in regions more subject to flooding

Whereas , in 1960, one third of the world population lived in developed countries, by 1995 these countries made up only $1 / 6$ of the world population. Furthermore, the proportion of population living in urban areas has greatly increased with all the associated problems of poverty, 
crowding, pollution and stress (Epstein and Leaf, 2007).

e. The rich have easier access to disaster warning, better and stronger homes and can recover faster. Population living under poor conditions, scarce resources, suffering already from socio-economic stress, in places where knowledge, expertise, services and infrastructure are already poor experience more suffering.

\section{Sea Level Rise :}

(may be associated with extreme weather events )

Predictions are that the expected rise in earth's surface mean temperature by $1.5-3^{\circ} \mathrm{C}$ will cause a sea level rise by $25-$ $110 \mathrm{~cm}$.

Effects vary according to local conditions, geographical location, association with extreme weather events and capacity of local community to respond; these include :

a. Death and injury due to flooding especially in low-lying coastal areas.

b. Indirect effects could include reduced drainage of coastal streams, thus increasing the risk of flooding. c. Loss of fertile agricultural land, salty water intrusion, water logging and reduced fish catch cause malnutrition.

d. Decreased availability of fresh water due to salty water intrusion.

e. Contamination of water supply due to interference with the drainage of the sewage system or contamination by chemicals from submerged waste dumps.

f. Destruction of tourist areas.

g. Population displacement, and socioeconomic decline with its effects on health. Effects will depend on the rate of displacement.

h. Political unrest due to reduced availability of food, loss of land , flooding, storm damage and the negative impact on economic activities like fishing, tourism, recreation and transportation.

Sea level rise by 1 meter will cause inundation of $10-15 \%$ of the Nile delta; Alexandria, Behaira Governorate and Port Said being the most affected (El Raie). Food production would drop severely and 8.5 million people could be displaced from their homes (Epstein and Leaf, 2007). 
Climate Change and Stratospheric Ozone :

Strictly speaking, Stratospheric Ozone Depletion is not part of Global Climate Change. There are, however, several recently described interactions between ozone depletion and greenhouse gasinduced warming (McMichael et al., 2003).

Several of the anthropogenic greenhouse gases are ozone depleting. Warming of the troposphere apparently induces stratospheric cooling which exacerbates ozone destruction. Loss of ozone itself augments cooling of the stratosphere.

Interactions between climate change and stratospheric ozone may delay recovery of the ozone layer by as long as $15-20$ years.

Predictions of future UVR exposures based on ozone depletion, behavioural changes and climate change are uncertain, but a recent analysis reports a likely increase by $5-10 \%$ in yearly UVR doses in Europe.

Increased UVR doses to the troposphere will enhance the formation of photochemical pollutants.

Increased UVB doses received by man has several effects:
On the skin, it causes malignant melanoma, non-melanocytic cancer, sun burn, chronic skin damage and photodermatoses.

On the eye, it can cause acute photokeratitis and photoconjunctivitis, climatic droplet keratopathy, pterygium, cancer of the cornea and conjunctiva, cataract (cortical, posterior subcapsular), uveal melanoma, acute solar retinopathy and macular degeneration.

Effects on immunity and infection include suppression of cell mediated immunity, increased susceptibility to infection, impairment of prophylactic immunization and activation of latent virus infection.

\section{References:}

I. الراعي ، م.ع. : التغيرات المناخية . آثارها على مصر وإمكانيات

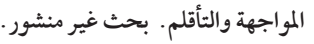

2. El Shahawi, M. A. (2008): Climate Change. Report to the National.Specialized Councils. Cairo, Egypt.

3. Epstein, P. (1997: Climate change. An issue summary of health and climate change. World Wildlife Fund. Washington, D.C., USA.

4. Epstein , P. R. (2005): Climate change and human health.New Eng. J. Med. 353: 1433-6.

5. Epstein, P. R. and Leaf, A. (2007): Biologic and medical Implications of global warming, in, Rom, W. N., ed. Environmental and Occupational Medicine, vol.4, $4^{\text {th }}$ ed. Wolters Kluwer, Lippincot, Williams and Wilkins. Pp. 1590-604. 
6. McMichael, A. J., Haines, A., Stoof, R. And Kovats, S. (1996): Climate Change and Human Health. World Health Organization, World Meteorological Organization and United Nations Environment Program. World Health Organization, Geneva.

7. McMichael, A. J., Campbell-Lendrum, D.H., Corvalan, C. F., Ebi, K.L., Githeko, A. K., Sheraga, J. D. And Woodward, A. (2003) : Cli- mate Change and Human Health. World Health Organization, Geneva.

8. Ministry of State for Environmental Affairs (2006) : Egypt State of The Environment Report 2006, Arab Republic of Egypt.

9. Nerlander, L. (2009) : Climate change and human health. Commission on Climate Change and Development. Stockholm, Sweden. 